\title{
Длинноволновые светодиоды в окне прозрачности атмосферы 4.6-5.3 мкм
}

\author{
(C) В.В. Романов, Э.В. Иванов, А.А. Пивоварова, К.Д. Моисеев , Ю.П. Яковлев \\ Физико-технический институт им. А.Ф. Иофрфе Российской академии наук, \\ 194021 Санкт-Петербург, Россия \\ " E-mail: mkd@iropt2.ioffe.rssi.ru
}

Поступила в Редакцию 3 октября 2019 г.

В окончательной редакции 10 октября 2019 г.

Принята к публикации 10 октября 2019 г.

\begin{abstract}
Разработана конструкция и технология получения методом газофазной эпитаксии из металлоорганических соединений асимметричной ступенчатой гетероструктуры InAs/InAs ${ }_{1-y} \mathrm{Sb}_{y} / \mathrm{InAsSbP}$ с предельным содержанием $\mathrm{InSb}$ (до $y=0.17$ ) в узкозонной активной области. Изучены электролюминесцентные характеристики длинноволновых светодиодов, созданных на основе предложенной гетероструктуры, которые излучали в спектральном диапазоне 4.6-5.3 мкм при комнатной температуре. Выявлено уменьшение по линейному закону квантовой эффективности электролюминесценции с ростом содержания InSb в активном слое полученных светодиодов. Показано преимущество использования асимметричной гетероструктуры для создания светодиодов с рабочей длиной волны более 4.5 мкм.
\end{abstract}

Ключевые слова: электролюминесценция, МОГФЭ, гетероструктуры, антимониды, светодиоды.

DOI: $10.21883 /$ FTP.2020.02.48906.9278

\section{1. Введение}

Создание полупроводниковых светодиодов, излучающих в длинноволновой части инфракрасного (ИК) спектра, открывает широкие возможности для разработки различных оптоэлектронных устройств, предназначенных для использования в окне атмосферной прозрачности 4.6-5.3 мкм [1,2]. Указанный спектральный диапазон содержит интенсивные полосы поглощения целого ряда азотосодержащих химических соединений, представляющих большой интерес с точки зрения промышленного газоанализа и экологического мониторинга: закись азота $\mathrm{N}_{2} \mathrm{O}$ (4.5 мкм), монооксид азота NO (5.3-5.4 мкм), диазосоединения $\mathrm{RN}_{2}$ (4.5-4.7 мкм), циан $(\mathrm{CN})_{2}$ (4.7 мкм), органические азиды $\mathrm{RN}_{3}$ (4.6-4.7 мкм), синильная кислота НCN (4.75 мкм) и др. [3,4]. Эпитаксиальные слои на основе твердых растворов в тройной системе $\mathrm{In}-\mathrm{As}-\mathrm{Sb}$ могут быть использованы для формирования активной области светоизлучающих приборов, работающих в среднем ИК-диапазоне на длинах волн свыше 4.5 мкм [5]. В зависимости от концентрации сурьмы в твердой фазе ширина запрещенной зоны твердого раствора $\mathrm{InAs}_{1-y} \mathrm{Sb}_{y}$ при комнатной температуре может изменяться в интервале энергий 0.35-0.1 эВ. Одновременно с этим происходит увеличение параметра кристаллической решетки наращиваемого тройного твердого раствора относительно соответствующего параметра подложки InAs. При малых величинах несоответствия эпитаксиальные слои $\operatorname{InAs}_{1-y} \mathrm{Sb}_{y}$ растут псевдоморфно, испытывая упругую деформацию. Однако при достижении некоторой критической величины рассогласования между активным слоем и матрицей возникает пластическая деформация сжатия, приводящая к образованию сетки дислокаций несоответствия на границах раздела эпитак- сиальных слоев между составными частями гетероструктуры [6]. В этом случае рациональное уменьшение количества слоев, составляющих активную область оптоэлектронного прибора, позволит минимизировать внутреннее напряжение в гетероструктуре при использовании твердых растворов InAs ${ }_{1-y} \mathrm{Sb}_{y}$ с большим содержанием антимонида индия. В настоящей работе рассмотрена возможность создания длинноволновых светодиодов с предельным содержанием сурьмы (до $y=0.17$ ) в активной области, работающих в ИК-диапазоне 4.6-5.3 мкм.

\section{2. Методика создания и исследования гетероструктур}

Гетероструктуры InAs/InAsSb/InAsSbP, которые включали в себя активный слой InAsSb толщиной 3 мкм и барьерный слой InAsSbP толщиной 1.2 мкм, были выращены методом газофазной эпитаксии из металлоорганических соединений (МОГФЭ). Осаждение проводилось в горизонтальном реакторе с резистивным типом нагрева при атмосферном давлении. В качестве подложки использовался нелегированный InAs (001) $\left(n=3 \cdot 10^{16} \mathrm{~cm}^{-3}\right)$. Перед процессом эпитаксии подложка отжигалась в реакторе в атмосфере арсина $\left(\mathrm{AsH}_{3}\right)$ при температуре $610^{\circ} \mathrm{C}$ в течение 30 мин. После отжига температура понижалась до $510^{\circ} \mathrm{C}$ и производилось осаждение активного слоя InAs $\mathrm{As}_{1-y} \mathrm{Sb}_{y}$, а затем верхнего барьерного слоя InAsSbP. Источниками компонент наращиваемых твердых растворов являлись металлоорганические соединения (триметилиндий - TMIn и триметилстибин - TMSb), а также гидридные газы (арсин $\mathrm{AsH}_{3}$ и фосфин - $\left.\mathrm{PH}_{3}\right)$. Состав газовой фазы при наращивании эпитаксиальных слоев $\operatorname{InAs}_{0.32} \mathrm{Sb}_{0.26} \mathrm{P}_{0.42}$ 


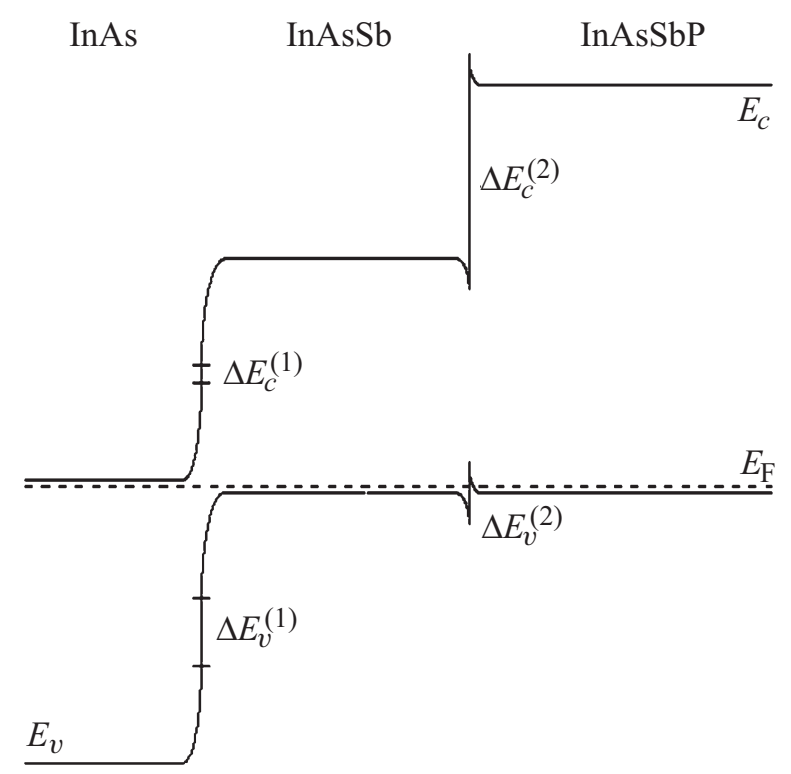

Рис. 1. Зонная энергетическая диаграмма ступенчатой (асимметричной) гетероструктуры II типа InAs/InAsSb/InAsSbP. $\Delta E_{C}^{(i)}$ и $\Delta E_{V}^{(i)}$ - энергетические разрывы на гетерограницах II типа для зоны проводимости $\left(E_{C}\right)$ и валентной зоны $\left(E_{V}\right)$ соответственно. $E_{\mathrm{F}}-$ уровень Ферми гетероструктуры в термодинамическом равновесии.

был одинаковым для всех исследуемых структур. Легирование верхних барьерных слоев проводилось в одинаковых технологических условиях. В качестве источника легирующей акцепторной примеси применялся диэтилцинк (DEZn).

B результате были получены гетероструктуры InAs/InAs ${ }_{1-y} \mathrm{Sb}_{y} / \mathrm{InAsSbP,}$ которые отличались друг от друга содержанием сурьмы в тройном твердом растворе в интервале составов $y=0.07-0.17$. Зонная энергетическая диаграмма для всех образцов представляла собой ступенчатую структуру с раздельным ограничением для носителей заряда как в валентной зоне, так и в зоне проводимости (рис. 1), в отличие от „симметричной“ двойной гетероструктуры (ДГС), в которой присутствуют два барьерных слоя InAsSbP, ограничивающие одновременно электроны и дырки в узкозонной активной области InAsSb [7].

Из полученных гетероструктур с помощью контактной фотолитографии и жидкостного химического травления были изготовлены светодиодные чипы размером $400 \times 400$ мкм. Контакт со стороны эпитаксиального слоя был создан в виде кольца шириной 30 мкм с внутренним диаметром 200 мкм, а со стороны подложки напылялся сплошной контакт. Кольцевой омический контакт создавался методом взрывной фотолитографии и термического напыления системы $\mathrm{Cr} / \mathrm{Au} / \mathrm{Ni} / \mathrm{Au}$ в высоковакуумной установке [8]. Дополнительное усиление данного контакта осуществлялось с помощью электрохимического осаждения. Для создания омического контакта со стороны подложки проводилось напыление системы $\mathrm{Cr} / \mathrm{Au} / \mathrm{Ni} / \mathrm{Au}$ сплошным слоем с последующим напылением системы $\mathrm{Cr} / \mathrm{Au}$. Суммарная толщина верхнего контакта составляла 2.5 мкм, а нижнего - 0.6 мкм. Затем контакты вжигались в атмосфере водорода. Светодиодные чипы монтировались на стандартные корпуса TO-18 подложкой к корпусу, чтобы обеспечить вывод излучения со стороны эпитаксиального слоя.

Исследования вольт-амперных и электролюминесцентных характеристик светодиодных гетероструктур проводились при комнатной температуре. Спектры электролюминесценции (ЭЛ) регистрировались с помощью автоматизированной установки на основе монохроматора DK-480 с дифракционной решеткой 150 штрих/мм (CVI Laser Corp.), селективного усилителя SR-810 (Stanford Research Systems) и фотовольтаического приемника InSb, охлаждаемого жидким азотом (Judson Co). Электролюминесценция возбуждалась прямоугольными импульсами тока с коэффициентом заполнения 50\% (квазинепрерывный режим) и частотой повторения 512 Гц. Амплитуда импульсов варьировалась в диапазоне 25-200 мА. При этом отрицательный потенциал был приложен к подложке $n$-InAs, а положи-

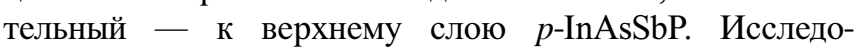
вание вольт-амперных характеристик также проводилось в квазинепрерывном режиме с частотой повторения 512 Гц.

\section{3. Экспериментальные результаты и обсуждение}

На рис. 2 представлены вольт-амперные характеристики (BАХ) исследуемых гетероструктур с различным содержанием сурьмы в узкозонном слое $\operatorname{InAs}_{1-y} \mathrm{Sb}_{y}$. $\mathrm{BAX}$ демонстрировали типичное диодное поведение с четко выраженными прямыми и обратными ветвями. По мере увеличения доли антимонида индия в активной

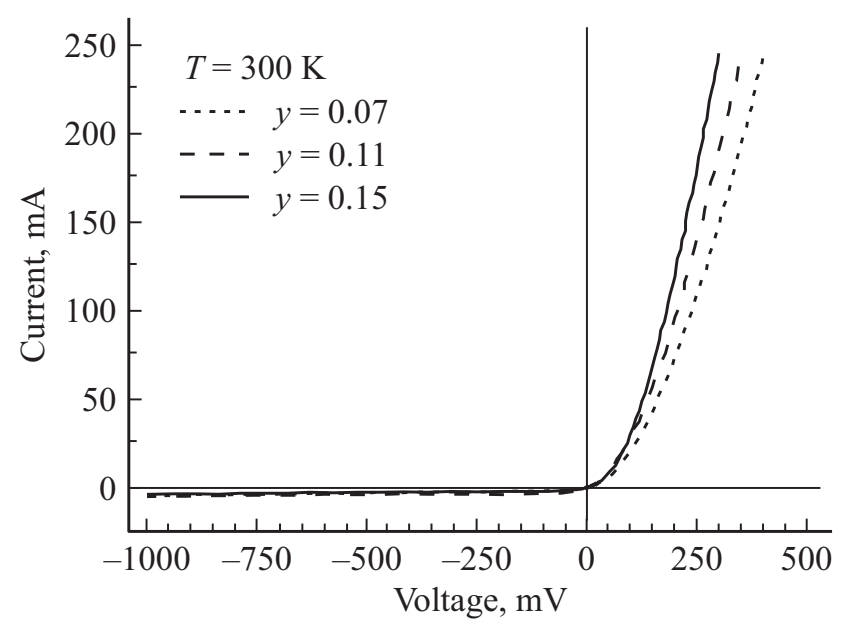

Рис. 2. Вольт-амперные характеристики гетероструктур InAs/InAs ${ }_{1-y} \mathrm{Sb}_{y} / \mathrm{InAsSbP}$ с различным содержанием сурьмы в тройном твердом растворе $y=0.07,0.11,0.15(T=300 \mathrm{~K})$. 


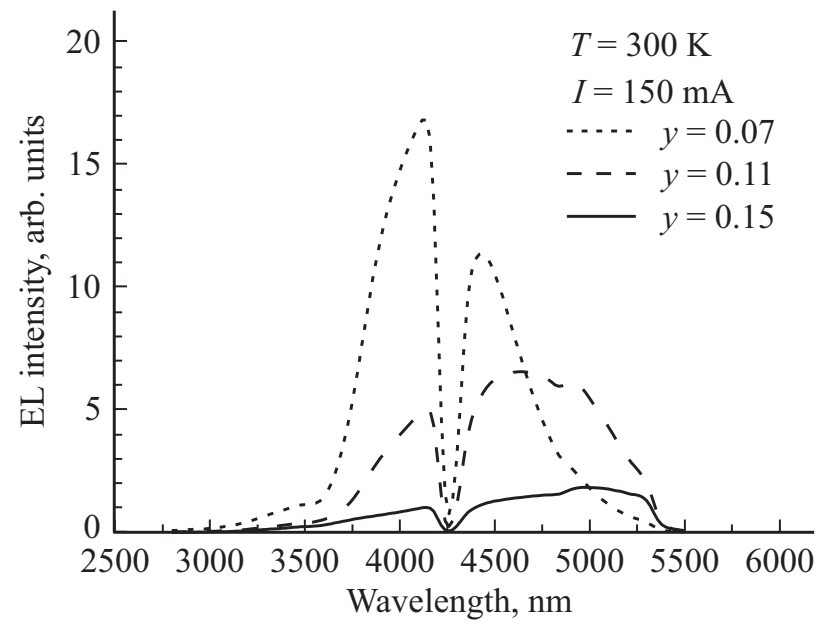

Рис. 3. Спектры ЭЛ для гетероструктур $\mathrm{InAs} / \mathrm{InAs}_{1-y} \mathrm{Sb}_{y} /$ InAsSbP с различным содержанием сурьмы в тройном твердом растворе $y=0.07,0.11,0.15$, полученные при токе накачки $i=150 \mathrm{MA}$ и $T=300 \mathrm{~K}$.

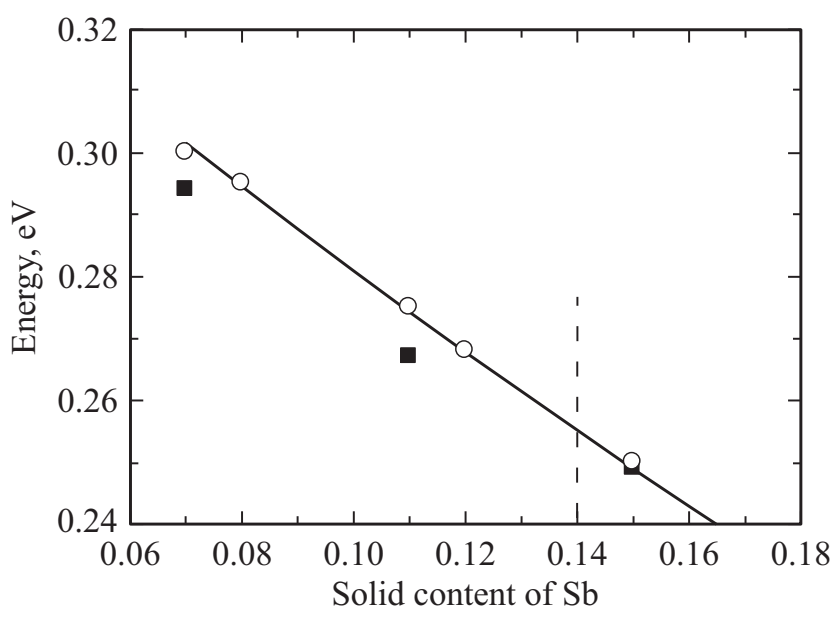

Рис. 4. Зависимость ширины запрещенной зоны и спектрального положения максимума основной полосы ЭЛ для гетероструктур с активным слоем $\operatorname{InAs}_{1-y} \mathrm{Sb}_{y}$ от содержания сурьмы в тройном твердом растворе при $T=300 \mathrm{~K}$. Светлые кружки - данные из работы [5], темные квадраты - экспериментальные результаты настоящей работы. Вертикальная пунктирная линия отвечает рассогласованию кристаллических решеток подложки и эпитаксиального слоя в $1 \%$.

области величина напряжения отсечки в прямой ветви BAX уменьшалась, что можно связать с уменьшением ширины запрещенной зоны тройного твердого раствоpa [5]. На рис. 3 показаны спектры ЭЛ этих же гетероструктур при одинаковом токе накачки. Для всех образцов в спектре ЭЛ кроме основной полосы излучения наблюдалась дополнительная, более коротковолновая, полоса вблизи 3.5 мкм, которая отвечает излучательным рекомбинационным переходам в объеме арсенида индия. Данная полоса была наиболее заметна для структур с содержанием сурьмы в активной области $y<0.11$. Увеличение содержания сурьмы выше указанного значе- ния приводило к подавлению полосы ЭЛ в окрестности 3.5 мкм, что может быть связано с уменьшением количества дырок, доставляемых приложенным внешним электрическим полем в область $n$-InAs через гетерограницу $n$-InAs $/ n$-InAsSb. Известно, что повышение содержания сурьмы в тройном твердом растворе приводит к увеличению энергетического разрыва в валентной зоне на гетерогранице II типа InAs/InAs ${ }_{1-y} \mathrm{Sb}_{y}$ [9] и, следовательно, к возрастанию потенциального барьера для дырок на данной границе раздела. В „симметричных“ ДГС слой InAsSbP между подложкой InAs и тройным твердым раствором InAsSb является дополнительным барьером для инжекции электронов в активную область светодиода, что приводит к увеличению интенсивности канала ЭЛ, связанного с излучательными переходами в подложке, и, следовательно, к ослаблению излучения из активной области.

На рис. 4 приведены значения энергии фотона в максимуме основной полосы ЭЛ для спектров, показанных на рис. 3, а также значения ширины запрещенной зоны активного слоя $\mathrm{InAs}_{1-y} \mathrm{Sb}_{y}$ исследуемых гетероструктур [5] в зависимости от содержания сурьмы $(y)$. Как видно из рисунка, для светодиодных гетероструктур с содержанием сурьмы в активной области $y=0.07$ и 0.11 экспериментальные точки, соответствующие максимуму основной полосы излучения в спектрах ЭЛ, располагались ниже кривой $E_{g}$ на $\sim 6$ мэВ. Для наиболее узкозонных образцов $(y=0.15)$, напротив, было характерно совпадение результатов настоящей работы и данных из работы [5].

Возможное объяснение наблюдаемой разницы в значениях энергии фотона в максимуме полосы ЭЛ и ширины запрещенной зоны может быть связано с условиями получения соответствующих образцов. Обсуждаемые в данной работе эпитаксиальные гетероструктуры подвергались дополнительному термическому воздействию в процессе постростовой обработки, что, по нашему мнению, могло повлиять на распределение акцепторной примеси в объеме образца. В результате постростового технологического нагрева атомы цинка диффундировали из барьерного слоя InAsSbP в глубь эпитаксиальной структуры, и область $p-n$-перехода сместилась в слой твердого раствора InAsSb. Тогда основная полоса в спектрах ЭЛ может быть приписана излучательным переходам в узкозонном слое $\mathrm{InAs}_{1-y} \mathrm{Sb}_{y}$ через примесные акцепторные состояния в запрещенной зоне тройного твердого раствора.

Следует подчеркнуть, что смещение $p$ - $n$-перехода наблюдалось только для образцов с содержанием антимонида индия $y<0.14$ и, возможно, данная особенность связана с кристаллическим совершенством активной области. В работе [5] было показано, что содержание антимонида индия в тройном твердом растворе $\mathrm{InAs}_{1-y} \mathrm{Sb}_{y}$ выше 0.14 отвечает рассогласованию параметров решетки для матрицы и узкозонного активного слоя равному $1 \%$, что приводит к формированию дислокаций несоответствия и релаксации внутренних напряжений на 
границах раздела активной области и барьерных слоев. Можно предположить, что при дальнейшем увеличении степени рассогласования между активной областью и матрицей существенно возрастет плотность дефектов, что в свою очередь будет препятствовать диффузии примесных атомов $(\mathrm{Zn})$ в глубь активной области светодиода. В подтверждение нашего предположения в эксперименте мы наблюдали совпадение спектрального положения максимума основной полосы ЭЛ и значения ширины запрещенной зоны твердого раствора $\mathrm{InAs}_{1-y} \mathrm{Sb}_{y}$ для составов с высоким содержанием сурьмы $y>0.14$ (см. рис. 4 ).

Как видно из рис. 3, исследуемые гетероструктуры демонстрировали уменьшение интенсивности ЭЛ с ростом содержания антимонида индия в активном слое. Так как ширина запрещенной зоны активного слоя для данных светодиодных структур зависит от содержания $\mathrm{InSb}$, можно получить зависимость интенсивности ЭЛ от длины волны в максимуме спектра ЭЛ светодиода. На рис. 5 приведены сравнительные результаты для ИК-светодиодов, производимых компанией АИБИ на основе „симметричных“ ДГС [10], и светодиодов на основе „асимметричных“ гетероструктур, рассматриваемых в данной работе. Отметим, что наблюдаемые зависимости интенсивности ЭЛ можно аппроксимировать прямыми линиями. При этом экстраполяция эмпирической прямой для „симметричных“ ДГС пересекает ось абсцисс в точке $\lambda=4.7$ мкм. Это свидетельствует о том, что использование таких гетероструктур для создания светодиодов, излучающих в спектральной области $\lambda>4.7$ мкм, сопряжено с серьезными проблемами. Экспериментальные результаты настоящей работы также показывают линейную зависимость интенсивности ЭЛ с ростом содержания антимонида индия в активном слое, но с меньшим наклоном к оси абсцисс, что позволяет продвинуться в более длинноволновую область ИК-спектра (рис. 5). В итоге были получены светодиоды с максимумом ЭЛ на длине волны $\lambda=5.1$ мкм, работающие при комнатной температуре, с выходной мощностью $P=1$ мкВт при токе накачки $i=150 \mathrm{MA}$.

Как можно видеть из рис. 5, образцы на основе „симметричных“ ДГС демонстрировали более высокие значения интенсивности выходного излучения в спектральной области в окрестности 4.3 мкм по сравнению со ступенчатыми гетероструктурами. Это объясняется наличием барьерного слоя InAsSbP для электронов со стороны подложки, который способствует удержанию носителей заряда в активной области светодиода. С другой стороны за счет изгиба зон проводимости на гетерогранице InAsSbP/InAsSb формируется потенциальный барьер для инжекции электронов в активную область, и при увеличении рассогласования между этими слоями с ростом концентрации антимонида индия в тройном твердом растворе качество данной гетерограницы может существенно влиять на транспорт носителей заряда через нее. Следовательно, отсутствие этого барьерного слоя с дислокационной

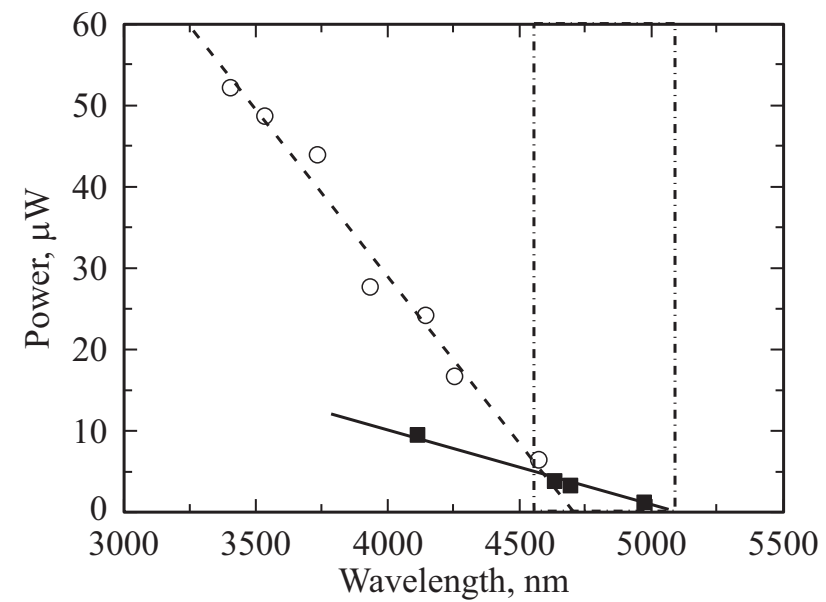

Рис. 5. Зависимость выходной оптической мощности светодиодов от длины волны в максимуме спектра ЭЛ при токе накачки $150 \mathrm{MA}$ и $T=300 \mathrm{~K}$. Светлые кружки - данные из [10], темные квадраты - экспериментальные результаты настоящей работы. Штрихпунктирные линии ограничивают область окна атмосферной прозрачности 4.6-5.3 мкм.

гетерограницей InAsSbP/InAsSb обеспечивает беспрепятственную инжекцию электронов в активную область. Кроме того, предложенная ступенчатая (асимметричная) гетероструктура InAs/InAs ${ }_{1-y} \mathrm{Sb}_{y} / \mathrm{InAsSbP}$ для составов $y>0.11$ содержит два гетероперехода II типа [5,8], каждый из которых образует потенциальный барьер для определенного сорта носителей заряда в активной области: InAs/InAsSb - для дырок и InAsSb/InAsSbP — для электронов. Такой дизайн зонной энергетической диаграммы гетероструктуры позволяет расширить рабочий диапазон длин волн для светодиодов на основе объемных слоев $\mathrm{InAsSb}$ до $\lambda=5.2$ мкм и перекрыть окно прозрачности атмосферы 4.6-5.3 мкм. Более того, данная светодиодная конструкция обеспечивает получение излучения в квазинепрерывном режиме в отличие от структур на основе тройных слоев с большим содержанием сурьмы $(y=0.25)$, которые работали в импульсном режиме [11].

\section{4. Заключение}

Таким образом, предложена асимметричная гетероструктура на основе сильно рассогласованных слоев узкозонных твердых растворов в системе $\mathrm{In}-\mathrm{As}-(\mathrm{Sb}, \mathrm{P})$ с предельным содержанием антимонида индия в активной области (до $y=0.17$ ), наращенных на подложке InAs (001), для создания длинноволновых светодиодов, работающих в окне прозрачности атмосферы 4.6-5.3 мкм. Полученные гетероструктуры демонстрировали более слабую зависимость интенсивности ЭЛ от состава активного слоя по сравнению с „симметричными“ ДГС и работали в квазинепрерывном режиме накачки в отличие от структур на основе активных слоев с пошаговым изменением состава. 


\section{Финансирование работы}

Работа выполнена при частичной поддержке международного проекта РФФИ НЦИИЛ_а № 17-52-16029 и гранта Президиума РАН „Наноструктуры: физика, химия, биология, основы технологий“.

\section{Конфликт интересов}

Авторы заявляют, что у них нет конфликта интересов.

\section{Список литературы}

[1] В.Е. Зуев. Распространение видимых и инфракрасных волн в атмосфере (М., Сов. Радио, 1970) с. 325.

[2] Г.Г. Ишанин, Э.Д. Панков, А.Л. Андреев, Г.В. Польщиков. Источники и приемники излучения (СПб., Политехника, 1991) c. 240.

[3] R.H. Pierson, A.N. Fletcher, E.St.C. Gantz. Analyt. Chem., 28, 1218 (1956).

[4] Б.Н. Тарасевич. ИК-спектры основных классов органических соединений. Справочные материалы (М., Изд-во МГУ, 2012) с. 55.

[5] В.В. Романов, Э.В. Иванов, К.Д. Моисеев. ФТТ, 61, 1746 (2019).

[6] J.H. van der Merwe. Phys. Rev. B, 37, 2892 (1988).

[7] Н.В. Зотова, С.С. Кижаев, С.С. Молчанов, Т.И. Воронина, Т.С. Лагунова, Б.В. Пушный, Ю.П. Яковлев. ФТП, 37, 980 (2003).

[8] В.В. Романов, И.А. Белых, Э.В. Иванов, П.А. Алексеев, Н.Д. Ильинская, Ю.П. Яковлев. ФТП, 53, 832 (2019).

[9] S.H. Wei, A. Zunger. Phys. Rev. B, 52, 12039 (1995).

[10] http://www.ibsg.ru

[11] Н.В. Зотова, С.А. Карандашев, Б.А. Матвеев, М.А. Ременный, Н.М. Стусь, Н.Г. Тараканова. ФТП, 39, 230 (2005).

Редактор А.Н. Смирнов

\section{Long-wavelength LEDs in the atmosphere transparency window 4.6-5.3 $\mu \mathrm{m}$}

V.V. Romanov, E.V. Ivanov, A.A. Pivovarova, K.D. Moiseev, Yu.P. Yakovlev

loffe Institute, 194021 St. Petersburg, Russia

Abstract A design and technology have been developed for the preparation of an asymmetric stepwise InAs/InAs ${ }_{1-y} \mathrm{Sb}_{y} / \mathrm{InAsSbP}$ heterostructure with an ultimate InSb content (up to $y=0.17$ ) in the narrow-gap active region by vapor-phase epitaxy from metalorganic compounds. The electroluminescent characteristics of long-wavelength LEDs based on the proposed heterostructure, which emitted in the spectral range of $4.6-5.3 \mu \mathrm{m}$ at room temperature, were studied. A linear decrease in the quantum efficiency of electroluminescence with an increasing InSb content in the active layer of the obtained LEDs was revealed. The advantage of using of the asymmetric heterostructure to create LEDs with a working wavelength of more than $4.5 \mu \mathrm{m}$ has been shown. 